\title{
Evaluation of the effects of adipose-derived mesenchymal stem cells on intraperitoneal adhesions
}

\author{
Erdal Uysal ${ }^{1}$, Mehmet Dokur ${ }^{2}$, Türkay Kırdak ${ }^{3}$, Akif Kurt ${ }^{4}$, Mehmet Karada $\breve{g}^{5}$
}

\section{ABSTRACT}

\section{Cite this paper as:} Uysal E, Dokur M, Kirdak

T, Kurt A, Karadağ M. Evaluation of the effects of adipose-derived mesenchymal stem cells on intraperitoneal adhesions. Turk J Surg 201834 (3): 184-190.

'Department of General Surgery, Sanko University School of Medicine, Gaziantep, Turkey ${ }^{2}$ Clinic of Emergency Medicine, Necip Fazıl City Hospital, Kahramanmaraş, Turkey ${ }^{3}$ Department of General Surgery, Uludağ University School of Medicine, Bursa, Turkey

${ }^{4}$ Department of Pharmacology, Kahramanmaraş Sütçü İmam University School of Medicine, Kahramanmaraş, Turkey ${ }^{5}$ Department of Biostatistic and Medical Informatics, İnönü University Health Sciences Institue, Malatya, Turkey

\section{Corresponding Author} Erdal Uysal e-mail:drerdaluysal@hotmail.com

Received: 10.03.2017 Accepted: 06.07.2017

Available Online Date: 31.08 .2018

CCopyright 2018 by Turkish Surgical Association Available online at www.turkjsurg.com
Objectives: The goal was to examine the efficiency of local implementation of adipose-derived mesenchymal stem cells, which have an anti-inflammatory effect, in preventing the intra-abdominal adhesions in rats.

Material and Methods: Twenty-one Wistar albino rats were randomly divided into 3 groups, 7 rats in each: Group 1 was defined as the control group, Group 2 as the sham group, and Group 3 as the adipose-derived mesenchymal stem cell group. A $6 \mathrm{~cm}$ mid-abdomen incision in the all the rats was performed. The cecum serosa and sub-serosa were injured by rubbing with a gauze. No agent was applied intraperitoneally for the rats in Group $1 ; 1.5 \mathrm{~mL}$ saline and $2 \times 10^{6} / \mathrm{kg}$ allojenic adipose-derived mesenchymal stem cells in the $1.5 \mathrm{~mL}$ saline were injected into peritoneum of rats in Groups 2 and 3, respectively. Laparotomy was performed on the $14^{\text {th }}$ day. Adhesion scores, histopathological examination, E-cadherin expression, and the tissue hydroxyproline level were evaluated.

Results: The general adhesion score and collagen deposition in Group 3 were found to be significantly higher than in Groups 1 and 2 ( $p=0.003$ and $p=0.009$, respectively). In the inflammatory cell comparison, a significant decrease was found in Group 3 in proportion to Groups 1 and 2 ( $p=0.001, p=0.005$, respectively). The E-cadherin levels were found to be higher in Group 3 ( $p=0.003$ ).

Conclusion: Severe adhesion was observed in the adipose-derived mesenchymal stem cells group. Collagen intensity and E-Cadherin expression also increased in the adipose-derived mesenchymal stem cells group. The anti-inflammatory effect was also seen in the adipose-derived mesenchymal stem cells group.

Keywords: E-cadherin, rat, hydroxyproline, peritoneal adhesion, stem cells

\section{INTRODUCTION}

Intraperitoneal adhesions that may develop after a great number of abdominal operations is an important problem that surgeons have to deal with after the abdominal surgical procedures. Although the incidence varies between $67 \%$ and $93 \%$, the incidence of cases requiring surgical intervention due to intraperitoneal adhesion is $15 \%-18 \%(1,2)$. The development of minimal invasive methods such as laparoscopy and their common usages decreased these rates (3). Intraperitoneal adhesions lead to hospitalization and surgical intervention due to mechanic ileus and pelvic pain. Furthermore, the intraperitoneal adhesions may cause secondary infertility in women during the fertility age (4). Since the exploration is very difficult in operations performed due to the adhesion, the iatrogenic injuries may be seen more frequently. Consequently, these complications lead to mortality and morbidity. Moreover, one of the most important results of adhesion-caused ileus is the increase in workforce loss and patient costs. For instance, in a study that has been carried out in the United States, it has been reported that the cost of surgeries performed due to the intraperitoneal adhesions was US\$1.3 billion in a year (5).

To decrease and prevent the adhesions, the adhesion-barrier agents such as carboxmethylcellulose, steroids, and non-steroidal anti-inflammatory drugs, immunosuppressive drugs, clinoleic against, high molecular weight hyaluronic acid and low molecular weight hydroxypropyl methylcellulose, fibrin destruction agents, recombinant tissue plasminogen activator, bevacizumab, and Vitamin-E have been utilized (6-10). Different results have been reported for these agents. Except for the adhesion-barrier, others could not be put into the practice. Therefore, preventing the intraperitoneal adhesions and dealing with them have constantly remained on the agenda of surgeons interested in abdominal surgery.

It has been reported that post-operative inflammatory responses play a significant role in the formation of adhesions (11). The inflammatory response, especially the suppression of TGF- $\beta 1$ and IL- 6 , may play an effective role in decreasing the intraperitoneal adhesion (12). Therefore, the anti-inflammatory feature of the selected chemical agent to prevent the peritoneal adhesion becomes very important. Adipose derived mesenchymal stem cells (ADSCs) show an anti-inflammatory effect by decreasing the inflammation in tissues $(13,14)$. Under the light of these observations, it can be hypothesized that ADSCs may decrease or prevent the adhesion formation by exhibiting the anti-inflammatory effect in the development of postoperative adhesions. In this study, the goal was to evaluate the effect of ADSCs on intraperitoneal adhesions that have an anti-inflammatory effect and on the intra-abdominal adhesions in rats. 


\section{MATERIAL AND METHODS}

The present study was approved by the local ethic committee. The protocol was approved by the Animal Ethics Review Committee (Permit number 2016/01-02). All experiments were conducted in compliance with the relevant laws and institutional guidelines.

\section{Rat groups}

Twenty-one female Wistar albino rats weighing between 260 and $280 \mathrm{gr}$ were randomly divided into 3 groups, 7 rats in each: Group 1 was defined as the control group, Group 2 as Sham, and Group 3 as the ADSCs group. All rats were females to provide standardization in the study.

The cecum serosa of the rats was injured with a sterile gauze during laparotomy. For the rats in Group 1, no agent was implemented intraperitoneally. For the rats in Group 2, $1.5 \mathrm{ml}$ saline was locally injected into the peritoneum. For the rats in Group 3, $2 \times 10^{6} / \mathrm{kg}$ allojenic ADSCs in the $1.5 \mathrm{~mL}$ saline were injected locally into the peritoneum.

\section{Anesthesia and Surgical Technique}

Rats were kept between $18-24^{\circ} \mathrm{C}$ ( 12 hours of day-night cycle) in cages (4-6 rats in each) with free water and food intake. Standard rat food and water were given to the rats. Before the operation, rats were fasting for 6 hours. As the anesthetics, ketamine (Ketalar, Pfizer, Turkey) 75 mg/kg and Xylazine $10 \mathrm{mg} / \mathrm{kg}$ (Rompun, Bayer AG, Leverkusen, Germany) were given intraperitoneally. For asepsis, polyvinylpyrolidone (polyvidon-iodine) 10\% was used. Ceftriaxone $100 \mathrm{mg} / \mathrm{kg}$ was applied for the purpose of intramuscular prophylaxis. For postoperative analgesia control, a $0.25 \%$ bupiviocaine incision was implemented in all the rats. For liquid losses, $10 \mathrm{mg} / \mathrm{L} 0.09 \% \mathrm{NaCl}$ was subcutaneously applied to all the rats. After the surgery, the rats were placed into separate cages and then followed up. Five hours after the surgery, the food and water intake was allowed.

After anesthesia, a $6 \mathrm{~cm}$ mid-abdomen incision was made in the rats. The cecum serosa and sub-serosa were injured by rubbing with a gauze. After the experimental procedures in the groups, the skin was closed with $4 / 0$ polyglactin sutures subcutaneously.

\section{ADSCs Extraction}

To obtain ADSCs, 10- to 12-week-old Wistar albino rats weighing between 270 and $300 \mathrm{~g}$ were used. After the ketamine hydrochloride $(75 \mathrm{mg} / \mathrm{kg}$ iM) and xylazine hydrochloride (10 $\mathrm{mg} /$ $\mathrm{kg}$ iM) anesthesia, the inguinal fatty tissues were taken (3-5 $\mathrm{cm}^{3}$ ). After washing the fatty tissue with a phosphate buffer solution (PBS, Sigma Aldrich, St. Louis, MO, USA) containing penicillin-streptomycin, the tissue was cut into small pieces. After 1 hour of enzymatic degradation at $37^{\circ} \mathrm{C}$ with $5 \mathrm{ml}$ Type I collagenase ( $1 \mathrm{mg} / \mathrm{mL}$, Sigma), $20-30 \mathrm{~mL}$ Low Glucose Dulbecco's Modified Eagle's Medium (L-DMEM, Gibco) with 1\% penicillin-streptomycin (PS, Sigma), 1\% L-glutamine (Sigma), and $10 \%$ fetal bovine serum (FBS, Gibco) were included. The mixture was centrifuged at $1.500 \mathrm{rpm}$ for 10 minutes, and after removing the supernatant portion and by adding $15-20 \mathrm{~mL}$ of medium on the cell pellet, the centrifuge was continued for 10 min. at $1.200 \mathrm{rpm}$. After removing the supernatant portion, 12 $\mathrm{mL}$ of medium was added on the ADSC pellet and then, within a $75 \mathrm{~cm}^{2}$ flask, incubated in a drying oven at $37^{\circ} \mathrm{C}$ with $5 \% \mathrm{CO}_{2}$. The ADSC cultures were used after the third passage.
Evaluation of the Adhesions and Tissue Sampling

On the $14^{\text {th }}$ day, surgery was performed in rats under intraperitoneal anesthesia with ketamine (Ketalar, Pfizer, Turkey) $75 \mathrm{mg} /$ $\mathrm{kg}$ and xylazine $10 \mathrm{mg} / \mathrm{kg}$ (Rompun, Bayer AG, Leverkusen, Germany). For the rats under anesthesia, to prevent the adhesioncaused injuries and to evaluate the adhesions on incision, laparotomy was performed via left paramedian incision.

A researcher, who did not know which group the rats belonged to, rated the rats on the scale between 0 and 9 points, and the levels of intra-abdominal adhesions were scored (15). In the assessment, the severity and the level of adhesion in the defect region were scored. The general score was calculated by adding up these three parameters.

After the rating, tissue samples were taken from the cecum and adjacent region adhesions to perform the histopathologic and other examinations. The samples taken were divided into two equal parts. One part of the tissue samples was fixed with $1 \mathrm{cc}$ physiological saline solution, and kept at $-80^{\circ} \mathrm{C}$ for hydroxyproline determination. The remaining part was fixed in formaldehyde for a histopathological examination. All rats were sacrificed by investigators via cervical dislocation.

\section{Histopathologic Analysis}

Histopathologic analyses were performed by the same pathologist. The pieces were prepared in a paraffin block, and their thin sections were analyzed under the light microscope with hematoxylin-eosin staining; the images were recorded via the computer. The histopathologic staging was performed in accordance with the Ehrlich-Hunt model (16) (Table 1).

In this model, the assessment criteria were determined to be inflammatory cells, fibroblast, neovascularization, and the collagen level. The cellular and histopathologic scoring were semiquantitatively determined to be at the fourth level. Separate calculations were performed for inflammatory cells, fibroblast proliferation, neovascularization, and the collagen deposition.

\section{Immunohistochemical Analysis}

For the immunohistochemical analysis, tissue samples were taken from all the rats in study groups and the control group. For the sections, the formalin fixation, paraffin treatment, and blocking were performed, and then, the immunohistochemical staining was carried out. In the tissues of different groups, the level of E-cadherin was semi-quantitatively determined (absent (0), slight (1): up to $20 \%$ positive; moderate (2): $21 \%$ 50\% positive; potent (3): 51\%-100\%).

\section{Tissue Hydroxyproline Level Determination}

The hydroxyproline content of the tissues was determined using the Hydroxyproline Assay Kit from Sigma (Cat. No: MAK008). The assay method is based on the reaction of oxidized hydroxyproline with 4-dimethylaminobenzaldehyde (DMAB) to give a colorimetric product at $560 \mathrm{~nm}$ (1). To explain briefly, $100 \mu \mathrm{L}$ of water was added on $10 \mathrm{mg}$ of wet tissue, and homogenization was performed by a sonicator equipped with a microtip (Bandelin, Germany) at the amplitude of $25 \%$ ( 0.7 s on, 0.2 s off cycle). Sonication was continued until the tissue suspension became completely homogeneous, which usually took approximately 1-2 min of total sonication time. $100 \mu \mathrm{L}$ of homogenized tissue sample was mixed with $100 \mu \mathrm{L}$ of concentrated $\mathrm{HCl}(12 \mathrm{M})$, and 
the mixture was hydrolyzed at $120^{\circ} \mathrm{C}$ for 3 hours. Once the hydrolysis was complete, the samples were centrifuged at 13,000 $\mathrm{g}$ for $10 \mathrm{~min}$, and $20 \mu \mathrm{L}$ of each hydrolysate was transferred into the wells of a 96 -well plate. The plate was incubated at $60^{\circ} \mathrm{C}$ for 3-4 hours to dry the samples completely. This was followed by the addition of $100 \mu \mathrm{L}$ chloramine $\mathrm{T}$ solution to each well and incubation for $5 \mathrm{~min}$ at the room temperature for the oxidation of hydroxyproline. Afterwards, $100 \mu$ of the DMAB reagent was added into the wells, and the plate was incubated at $60^{\circ} \mathrm{C}$ for $90 \mathrm{~min}$. A microplate reader (Multiskan GO, Thermofisher Scientific) was used to measure the absorbance at $560 \mathrm{~nm}$ immediately after incubation. The hydroxyproline standards with known concentration were also measured in a similar way. The amount of the hydroxyproline content was calculated using a standard curve that was generated from the absorbance values of standards. The results were expressed as micrograms of hydroxyproline per milligrams of wet tissue $(\mu \mathrm{g} / \mathrm{mg})$.

\section{Statistical Analysis}

For statistical analyses, Statistical Package for the Social Sciences (SPSS) version 13.0 (SPSS Inc.; Chicago, IL, USA). The

\section{Table 1. Histologic Grading Scale*}

\begin{tabular}{|lc|}
\hline Grade & $\begin{array}{c}\text { Inflammatory cell/fibroblast/ } \\
\text { neovascularization/collagen }\end{array}$ \\
\hline 1 & A small amount and scattered \\
\hline 2 & A small amount and all areas \\
\hline 3 & A lot and scattered \\
\hline 4 & A lot and all areas \\
\hline *Ehrlich-Hunt Model & \\
\hline
\end{tabular}

Table 2. Comparison of the Group Adhesion Scores

\begin{tabular}{|lcccc|} 
& Group 1 & Group 2 & Group 3 & $\mathbf{p}^{*}$ \\
\hline General adhesion score & $6 \pm 1.1^{\mathrm{a}}$ & $4.4 \pm 1.1^{\mathrm{a}}$ & $7.5 \pm 1.2^{\mathrm{a}}$ & $=0.003$ \\
\hline Adhesion severity & $2.1 \pm 0.3$ & $1.7 \pm 0.4$ & $2.2 \pm 0.4$ & $=0.278$ \\
\hline Degree of adhesion & $1.7 \pm 0.7$ & $1.2 \pm 0.4^{\mathrm{a}}$ & $2.5 \pm 0.5^{\mathrm{a}}$ & $=0.038$ \\
\hline Participation percentage & $2.1 \pm 0.3$ & $1.4 \pm 0.5^{\mathrm{a}}$ & $2.7 \pm 0.4^{\mathrm{a}}$ & $=0.003$
\end{tabular}

*Kruskal-Wallis test: The results were given as the mean \pm standard deviation

aSubgroup comparison: Statistically significant groups

Table 3. Comparison of Histopathologic Findings and the Hydroxyproline Levels of Groups

\begin{tabular}{|lcccc} 
& Group 1 & Group 2 & Group 3 & $\mathbf{p}^{*}$ \\
\hline Inflammation & $3(3,4)^{*}$ & $2(3,3)^{*}$ & $1(2,2)^{*}$ & $0.001^{\mathrm{a}}$ \\
\hline Fibroblast activation & $3(3,4)$ & $3(3,4)$ & $3(4,4)$ & $0.135^{\mathrm{a}}$ \\
\hline Neovascularization & $3(3,4)$ & $3(3,4)$ & $3(4,4)$ & $0.189^{\mathrm{a}}$ \\
\hline Collagen deposition & $3(3,4)^{*}$ & $3(4,4)^{*}$ & $4(4,4)^{*}$ & $0.009^{\mathrm{a}}$ \\
\hline E-cadherin & $0.4 \pm 0.5^{*}$ & $0.14 \pm 0.3^{*}$ & $1.5 \pm 0.5^{*}$ & $0.003^{\mathrm{a}}$ \\
\hline
\end{tabular}

Hydroxyproline $(\mu \mathrm{g} / \mathrm{mg}) \quad 0.38 \pm 0.23 \quad 0.48 \pm 0.31 \quad 0.40 \pm 0.06 \quad 0.690^{* *}$

*Subgroup comparison: Statistically significant groups. Minimum (median, maximum)

**ANOVA

Group 1: Control; Group 2: Saline; Group 3: Adipose-derived mesenchymal stem cell
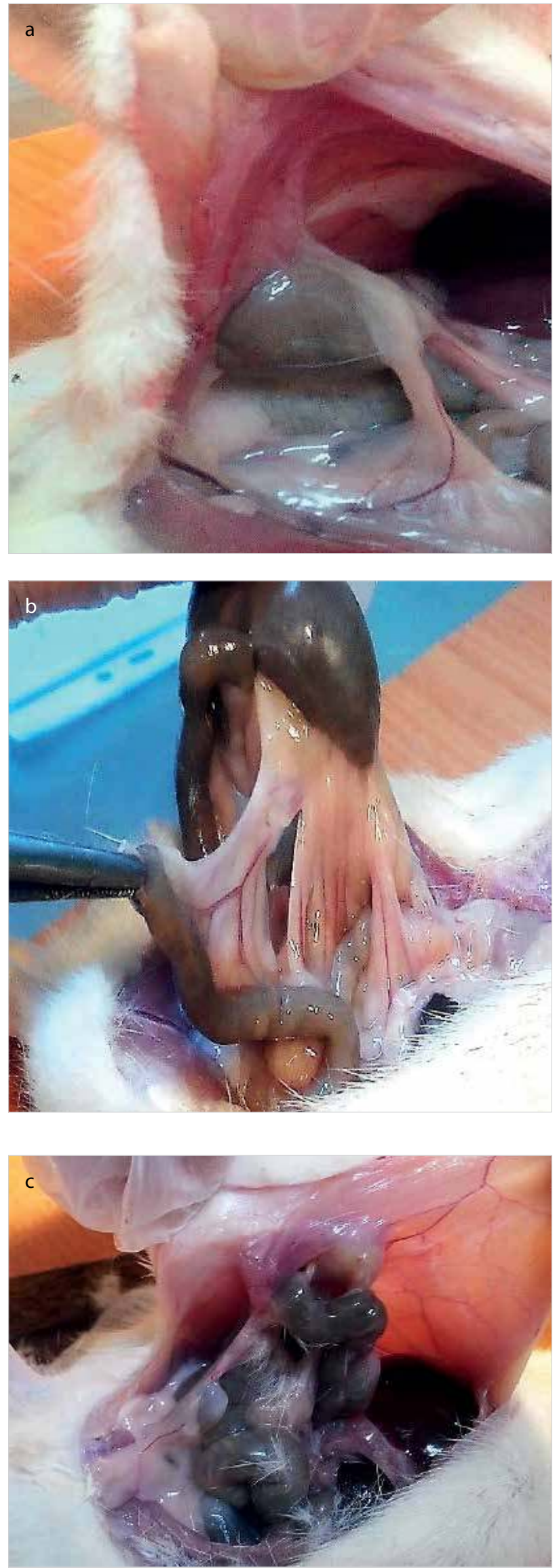

Figure 1. a-c. Macroscopic appearance of tissues. Control group: Intermediate increase adhesion is observed (a), Saline group: Intermediate increase adhesion is observed (b), Mesencimal stem cell group: Increased adhesion is observed (c) 
Kruskall-Wallis test was used in the semi-quantitative group comparisons. In the paired comparison, it was done using the Kruskal-Wallis (post hoc tests) and Sida-Dunn test. The analysis of variance was used in comparing the quantitative parameters. The Tukey test was employed for multiple comparisons. The results were given as the mean \pm standard deviation. The values $\mathrm{p}<0.05$ were considered significant.

\section{RESULTS}

\section{Adhesion Scores}

The general adhesion score was $6 \pm 1.1$ in Group 1, 4.4 \pm 1.1 in Group 2, and 7.5 \pm 1.2 in Group 3. The general adhesion score of Group 3 was found to be statistically significantly higher
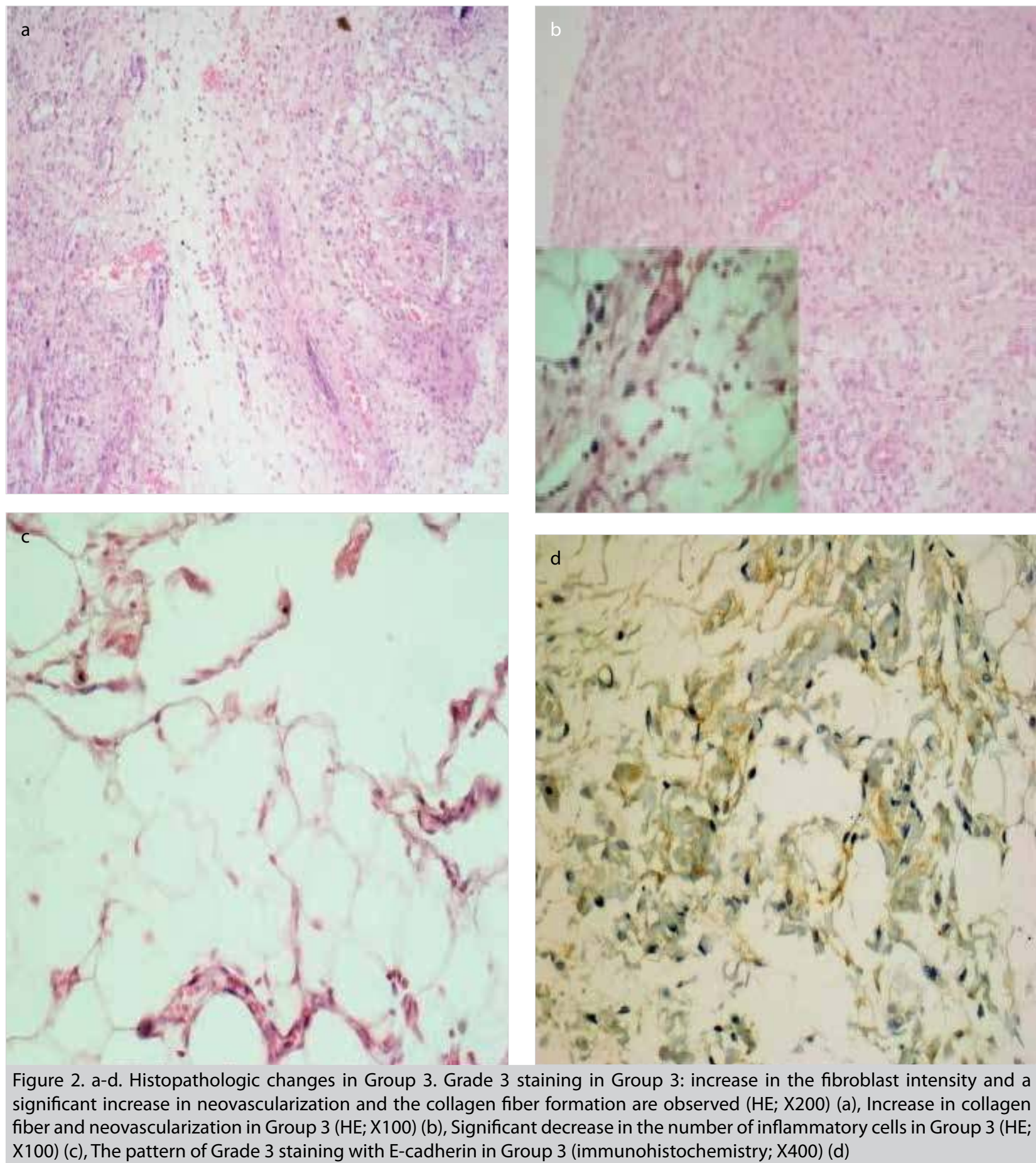

Figure 2. a-d. Histopathologic changes in Group 3. Grade 3 staining in Group 3: increase in the fibroblast intensity and a significant increase in neovascularization and the collagen fiber formation are observed (HE; X200) (a), Increase in collagen fiber and neovascularization in Group 3 (HE; X100) (b), Significant decrease in the number of inflammatory cells in Group 3 (HE; X100) (c), The pattern of Grade 3 staining with E-cadherin in Group 3 (immunohistochemistry; X400) (d)

compared to the Group 1 and Group 2 ( $p=0.003$ ). No statistically significant difference was found between the general adhesion scores of Group 1 and Group 2 ( $p>0.05$; Table 2, Figure 1).

\section{Histopathologic Analysis Results}

In neovascularization and fibroblast intensity, no statistically significant difference was observed between the groups. In terms of collagen deposition, the statistically significant increase was found in Group 3 in proportion to Groups 1 and 2 ( $p=0.009$ ). In inflammatory cell comparisons, a significant decrease was seen in Group 3 relative to Groups 1 and 2 $(p=0.001)$. No statistically significant difference was found between Group 1 and Group 2 ( $p>0.05$ ) (Table 3; Figure 2).

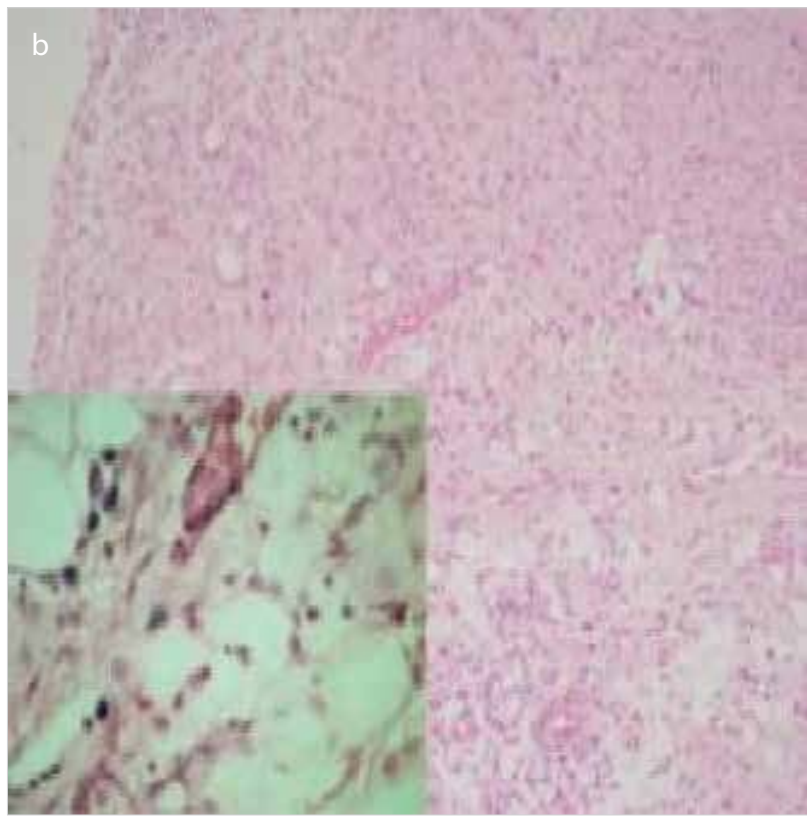




\section{Immunohistochemical Analysis Results}

In comparisons performed between the groups, the pattern of positive staining with E-cadherin was found to be statistically higher in Group 3 compared with Groups 1 and $2(p=0.003)$. No statistically significant difference was found between Group 1 and Group 2 ( $\mathrm{p}>0.05$ ) (Table 3).

\section{Tissue Hydroxyproline Level Results}

The hydroxyproline level was found to be $0.38 \pm 0.23 \mu \mathrm{g} / \mathrm{mg}$ in Group $1,0.48 \pm 0.31 \mu \mathrm{g} / \mathrm{mg}$ in Group 2, and $0.40 \pm 0.06 \mu \mathrm{g} / \mathrm{mg}$ in Group 3. No statistically significant difference was found between the groups $(p=0.69)$ (Table 3$)$.

\section{DISCUSSION}

Intraperitoneal adhesions are an important problem that surgeons have to cope with after the abdominal surgical procedures. The clinical situations caused by intraperitoneal adhesions and the complications, which develop due to intraperitoneal adhesions, lead to an increased mortality and morbidity (17). For this reason, preventing the intraperitoneal adhesions and dealing with the adhesions have constantly remained on the agenda of surgeons interested in the abdominal surgery. The studies have been carried out with many agents to prevent the adhesions. However, there is no consensus on the ideal agent to be used.

In the formation of postoperative intraperitoneal adhesions, damaged tissues and the fibrin deposits are responsible for the inflammation. The inflammatory process continues with the restoration of damaged tissues by the cells such as macrophages and fibroblast cells. The permanent fibrous adhesions are formed with collagen and other matrix proteins expressed from fibroblasts.

In the study by Sekiguchi et al. (18), it was reported that the bone marrow stem cells played an important role in the peritoneal restoration process and mesothelial remodeling. In that study, it was shown that the anti-inflammatory effect of the mesenchymal stem cells lasted for 14 days. In another study, the IL-10 cytokine having an inflammatory property has been found in the mesenchymal stem cell. The same study noted that the intraperitoneally injected mesenchymal stem cells suppressed the TGF- $\beta 1$ expression and prevented the phosphorylation of Smad 2 caused by TGF- $\beta 1$. These results indicate that the TGF- $\beta 1$ signal was suppressed, and consequently, the mesenchymal stem cells showed an anti-inflammatory effect (19).

Although the tissue repair function and the immunoregulation of mesenchymal stem cells (MSCs) have been known for a long time, their exact mechanisms of action are still not clear. Recent findings indicate that an intravenous injection of MSCs may attenuate the peritoneal injury by repairing mesothelial cells, reducing inflammation and fibrosis. There remains a controversy on the application of MSCs in peritonitis, and peritoneal injury is still being explored. Mesenchymal stem cells segregate many growth factors. They are the strongest mediators of the HGF and BMP-7 anti-fibrotic cytokines. They play a preventive role in the formation of peritoneal fibrosis (20). The secretion of TSG 6 by MSCs makes a major contribution to the therapeutic benefits of MSCs. Moreover, when mesenchymal stem cells have been transplanted into injured tissues, an improvement was achieved in neovascularization and wound healing (21). ADSCs have been shown to have an anti-inflammatory effect by decreasing inflammation in the tissue (14, 20). While planning our study, we were focused on that ADSCs would have an anti-inflammatory effect, decrease the intraabdominal adhesion, and might prevent it. Under the light of these clinical and experimental observations, ADSCs were used in the intra-abdominal adhesion model in our study.

In comparisons in terms of inflammatory cells, the inflammatory cell intensity was found to be significantly lower in the ADSC group in proportion to the control and saline groups. Mesenchymal stem cells also affect many immune cells in terms of proliferation and function. Moreover, they contribute to the immune modulation by assisting the regulatory T-cell production, and the inflammatory response decreases (14, 20). Also, both of the bone marrow-derived MSC and ADSCs decreased the leukocyte infiltration and protected the tissue from inflammation $(21,22)$. In a study, it has been determined that an intravenous ADSC injection lowered the inflammatory response and the inflammatory cytokine levels such as cyclooxygenase-2, IL-6, and tumor necrosis factor-a. These results revealed the anti-inflammatory property of ADSCs (23). A decrease in the inflammatory cell density was found in the ADSC group from our study in accordance with the previous studies.

In previous studies, it has been reported that mesenchymal stem cells increased the neovascularization and collagen level in tissues (18). Moreover, the increased collagen level may be correlated with an increase in the fibroblast intensity. Fibroblasts are responsible for the secretion of extracellular matrix proteins and collagen, and therefore, they play key role in wound healing. Parallel with the previous studies, we also found a significant increase in the ADSC group in proportion to the saline and control groups in terms of an increased collagen intensity. In our study, no statistically significant fibroblast intensity was found between the groups. However, fibroblast was relatively higher in the ADSC group. Mesenchymal stem cells can contribute to the regeneration in many organs (24). MSCs also increase the fibroblast regeneration. In our study, the increase in fibroblast intensity was thought to be correlated with the regenerative property of mesenchymal stem cells on the fibroblasts.

Hydroxyproline that constitutes the main component of collagen plays an important role in the collagen stabilization (25). The hydroxyproline level is used as an indicator of adhesion severity. An increased hydroxyproline level leads to an increase in peritoneal adhesion severity (26). In our study, the level of hydroxyproline was not found to be statistically significant in the groups. An increase in the general adhesion score in the ADSC group cannot be correlated with an increased hydroxyproline level.

Adipose derived mesenchymal stem cells produce too much cytokines, bioactive matters, extracellular matrix proteins, as well as adhesion molecules (20). In a study, it has been shown that the co-culture with ADSCs increased both the N-cadherin and E-cadherin expression (27). In our study, an increase was observed in the rate of positive staining with E-cadherin in the ADSCs group. E-cadherin is one of the molecules responsible for the intracellular adhesion and communication. An increase in the E-cadherin expression leads to an increase in the rate of cell-to-cell adhesion. Cellular adhesion molecules play an important role in the process of peritoneal adhesion formation. 
The increase in E-cadherin expression may contribute to the increase in general adhesion score found in the ADSC group.

According to our hypothesis, it was thought that ADSCs would decrease the adhesion by exhibiting an anti-inflammatory effect and might prevent the adhesions. Despite an anti-inflammatory response, it was observed that ADSCs led to severe and strong intraperitoneal adhesions. The ADSCs group had the highest general adhesion score. Although ADSCs showed a desired anti-inflammatory efficiency, it was observed that they increased the adhesions. An increase in the E-cadherin expression and collagen can be hold responsible for the adhesions.

\section{Study Limitations}

This study has several limitations. To the best of our knowledge, this is the first study in the literature that investigated the effects of ADSCs on the postoperative intraperitoneal adhesions formation. The ADSCs-associated histopathologic changes at the ultrastructural level need to be further analyzed. Therefore, further studies are needed to clarify the pathophysiological events. ADSCs were used $1-5 \times 10^{6}$ doses for different purposes and in different studies $(28,29)$. Although different time points could be considered, a single time point is used to evaluate the adhesion formation in this study. The vascular markers such as CD31 can be used for neovascularization. There are insufficient data on the rejection in allogeneic ADSCs. However, Kim et al. (30) studied immune reactions of allogenic adipogenic differentiated ADSCs. They showed that allogeneic adipogenic-differentiated ADSCs do not cause immunoreaction and maintain nonimmunogenicity. For this reason, they reported that allogenic ADSCs could be used safely in recipients. Since all these findings were obtained in vitro, there is an urgent need in vivo studies for the immune reaction and rejection of allogenic ADSCs. It is not known whether the allogenic ADSC used in our study caused rejection. Immunity can also be a response to the significant adhesion formation.

Adipose derived mesenchymal stem cells are not seen as an ideal agent for preventing the postoperative intraperitoneal adhesions. But, under the clinical conditions, where the formation of adhesions is desired, it can be used in the treatment such as closing the dead gaps via the formation of adhesion.

\section{CONCLUSION}

A severe adhesion was observed in the ADSCs-administered group. Also, the collagen intensity and E-cadherin expression increased in the ADSCs-administered group. The anti-inflammatory effect was also seen in the ADSCs group. The effect on the failure of adhesion improvement caused by an ADSCs intraperitoneal injection needs to be further analyzed. Further studies are needed to clarify the pathophysiological events.

Ethics Committee Approval: Ethics committee approval was received for this study from the Ethics Committee of Kahramanmaras Sutcu Imam University (2016/01-02).

Informed Consent: Not required in this study.

Peer-review: Externally peer-reviewed.

Author Contributions: Concept - E.U., A.H.K.; Design - M.D., E.U., T.K.; Supervision - E.U., T.K., M.D.; Resource - E.U., M.D.; Materials - E.U., A.H.K., M.D.; Data Collection and/or Processing - E.U., M.K., M.D.; Analysis and/or Reviews - T.K., A.H.K., M.K.; M.D., E.U.
Acknowledgements: We thank to Assistant Professor Dr. İbrahim Ibiloğlu for his endeavors and also we thank to the Staff of Experimental Animal Center of Kahramanmaras Sutcu Imam University.

Conflict of Interest: The authors have no conflicts of interest to declare.

Financial Disclosure: The authors declared that this study has received no financial support.

\section{REFERENCES}

1. Ouaissi M, Gaujoux S, Veyrie N, Deneve E, Brigand C, Castel B, et al. Post-operative adhesions after digestive surgery: their incidence and prevention: review of the literature. J Visc Surg 2012; 149: e104-e114. [CrossRef]

2. Weibel MA, Majno G. Peritoneal adhesions and their relation to abdominal surgery. A postmortem study. Am J Surg 1973; 126: 345-353. [CrossRef]

3. Takagi K, Araki M, Fukuoka H, Takeshita H, Hidaka S, Nanashima A, et al. Novel powdered anti-adhesion material: preventing postoperative intra-abdominal adhesions in a rat model. Int J Med Sci 2013; 10: 467-474. [CrossRef]

4. Stricker B, Blanco J, Fox HE. The gynecologic contribution to intestinal obstruction in females. J Am Coll Surg 1994; 178: 617620.

5. Ray NF, Denton WG, Thamer M, Henderson SC, Perry S. Abdominal adhesiolysis: inpatient care and expenditures in the United States in 1994. J Am Coll Surg 1998; 186: 1-9. [CrossRef]

6. Hoare T, Yeo Y, Bellas E, Bruggeman JP, Kohane DS. Prevention of peritoneal adhesions using polymeric rheological blends. Acta Biomater 2014; 10: 1187-1193. [CrossRef]

7. de la Portilla F, Ynfante I, Bejarano D, Conde J, Fernandez A, Ortega JM, et al. Prevention of peritoneal adhesions by intraperitoneal administration of vitamin E: An experimental study in rats. Dis Colon Rectum 2004; 47: 2157-2161. [CrossRef]

8. Tarhan OR, Eroglu A, Cetin R, Y Nce A, Bulbul M, Altuntas YR. Effects of seprafilm on peritoneal fibrinolytic system. ANZ J Surg 2005; 75: 690-692. [CrossRef]

9. Kirdak T, Uysal E, Korun N. Assessment of effectiveness of different doses of methylprednisolone on intraabdominal adhesion prevention. Ulus Travma Acil Cerrahi Derg 2008; 14: 188191.

10. Akcan A, Akgün H, Akyıldız H, Yılmaz N, Küçük C, Ok E, et al. Evaluation of low dose bevacizumab on adhesion formation and vascular endothelial growth factor expression in rats. Turk J Surg 2006; 22: 99-103.

11. Saed GM, Diamond MP. Molecular characterization of postoperative adhesions: the adhesion phenotype. J Am Assoc Gynecol Laparosc 2004; 11: 307-314. [CrossRef]

12. Jin $X$, Ren $S$, Macarak E, Rosenbloom J. Pathobiological mechanisms of peritoneal adhesions: The mesenchymal transition of rat peritoneal mesothelial cells induced by TGF- $\beta 1$ and IL- 6 requires activation of Erk1/2 and Smad2 linker region phosphorylation. Matrix Biol 2016; 51: 55-64. [CrossRef]

13. Wan CD, Cheng R, Wang HB, Liu T. Immunomodulatory effects of mesenchymal stem cells derived from adipose tissues in a rat orthotopic liver transplantation model. Hepatobiliary Pancreat Dis Int 2008; 7: 29-33.

14. Kim Y, Jo SH, Kim WH, Kweon OK. Antioxidant and anti-inflammatory effects of intravenously injected adipose derived mesenchymal stem cells in dogs with acute spinal cord injury. Stem Cell Res Ther 2015; 6: 229. [CrossRef]

15. Linsky CB, Diamond MP, Cunningham T, Constantine B, DeCherney $A H$, diZerega GS. Adhesion reduction in the rabbit uterine horn model using an absorbable barrier, TC-7. J Reprod Med 1987; 32: 17-20. 
16. Ehrlich HP, Tarver H, Hunt TK. Effects of vitamin A and glucocorticoids upon inflammation and collagen synthesis. Ann Surg 1973; 177: 222-227. [CrossRef]

17. Hassan WU, Greiser U, Wang W. Role of adipose-derived stem cells in wound healing. Wound Repair Regen 2014; 22: 313325. [CrossRef]

18. Sekiguchi Y, Hamada C, Ro Y, Nakamoto H, Inaba M, Shimaoka T, et al. Differentiation of bone marrowderived cells into regenerated mesothelial cells in peritoneal remodeling using a peritoneal fibrosis mouse model. J Artif Organs 2012; 15: 272-82. [CrossRef]

19. Ueno T, Nakashima A, Doi S, Kawamoto T, Honda K, Yokoyama Y, et al. Mesenchymal stem cells ameliorate experimental peritoneal fibrosis by suppressing inflammation and inhibiting TGF- $\beta 1$ signaling. Kidney Int 2013; 84: 297-307. [CrossRef]

20. Zeisberg M, Hanai J, Sugimoto H, Mammoto T, Charytan D, Strutz F, et al. BMP-7 counteracts TGF-beta1-induced epithelial-to-mesenchymal transition and reverses chronic renal injury. Nat Med 2003; 9: 964-968. [CrossRef]

21. Elman JS, Li M, Wang F, Gimble JM, Parekkadan B. A comparison of adipose and bone marrow-derived mesenchymal stromal cell secreted factors in the treatment of systemic inflammation. J Inflamm (Lond) 2014; 11: 1. [CrossRef]

22. Antunes M, Branco V, Diaz B, Morales M, Xisto D, Rocco P, et al. Mesenchymal stem cells derived from bone marrow present better effects on lung inflammation and remodeling compared with other sources in experimental asthma. Am J Respir Crit Care Med 2014; 189: 5291.
23. Ruszczak Z. Effect of collagen matrices on dermal wound healing. Adv Drug Deliv Rev 2003; 55: 1595-611. [CrossRef]

24. Mizuno H, Tobita M, Uysal AC. Concise review:adipose-derived stem cells as a novel tool for future regenerative medicine. Stem Cells 2012; 30: 804-810. [CrossRef]

25. Jenkins CL, Bretscher LE, Guzei IA, Raines RT. Effect of 3-hydroxyproline residues on collagen stability. J Am Chem Soc 2003; 125: 6422-6427. [CrossRef]

26. Wei G, Chen X, Wang G, Jia P, Xu Q, Ping G, et al. Inhibition of cyclooxygenase-2 prevents intra-abdominal adhesions by decreasing activity of peritoneal fibroblasts. Drug Des Devel Ther 2015; 19: 3083-3098.

27. Kim JY, Park CD, Lee JH, Lee CH, Do BR, Lee AY.Co-culture of melanocytes with adipose-derived stem cells as a potential substitute for co-culture with keratinocytes. Acta Derm Venereol 2012; 92: 16-23. [CrossRef]

28. Elhusseini FM, Saad MA, Anber N, Elghannam D, Sobh MA, Alsayed A, et al. Long Term Study of Protective Mechanisms of Human Adipose Derived Mesenchymal Stem Cells on Cisplatin Induced Kidney injury in Sprague-Dawley Rats. J Stem Cells Regen Med 2016; 12: 36-48.

29. Sheashaa H, Lotfy A, Elhusseini F, Aziz AA, Baiomy A, Awad S, et al. Protective effect of adipose-derived mesenchymal stem cells against acute kidney injury induced by ischemia-reperfusion in Sprague-Dawley rats. Exp Ther Med 2016; 11: 1573-1580. [CrossRef]

30. Kim I, Bang SI, Lee SK, Park SY, Kim M, Ha H. Clinical implication of allogenic implantation of adipogenic differentiated adiposederived stem cells. Stem Cells Transl Med 2014; 3: 1312-1321. [CrossRef] 